\title{
APPLICATION OF NEWLY DEVELOPED ROTATIONAL SENSOR FOR MONITORING OF MINING INDUCED SEISMIC EVENTS IN THE KARVINA REGION
}

\author{
Zdeněk KALÁB ${ }^{1,2) *}$, Jaromír KNEJZLÍK ${ }^{1)}$ and Markéta LEDNICKÁ ${ }^{1)}$ \\ 1) Institute of Geonics, Academy of Sciences of the Czech Republic, Studentská street 1768, CZ-70800, Ostrava- \\ Poruba, Czech Republic \\ ${ }^{2)}$ Department of Geotechnics and Underground Engineering, Faculty of Civil Engineering VŠB-Technical \\ University Ostrava, Ludvika Podéště 1875/17, CZ-708 33 Ostrava - Poruba, Czech Republic \\ *Corresponding author's e-mail: kalab@ugn.cas.cz
}

(Received July 2012, accepted January 2013)

\begin{abstract}
Classical Russian pendulum seismometer S-5-S was modified for recording of the rotational components of ground motion around the vertical or horizontal axes; the modified sensor is denoted here as S-5-SR. Experimental field testing of the S-5-SR sensor started in December 2010 in the Karvina coal region that is known as an area of intensive mining induced seismicity. First seismic station was installed in Doubrava village characterized by thick sedimentary layers. Next seismic station was installed in Orlova village, in different local geological conditions, i.e. in region without sedimentary layers. More than 200 mining induced seismic events were recorded on each seismic station during the period of six months of seismic monitoring. The recorded wave patterns confirm the existence of rotational ground motion components in this region; the strongest recorded value of this component exceeded $1 \mathrm{mrad} . \mathrm{s}^{-1}$. Analysis of the obtained records is presented in this paper.
\end{abstract}

KEYWORDS: rotational ground motion, rotational sensor, seismic monitoring, mining induced seismicity

\section{INTRODUCTION}

It follows from the theory of seismic waves' origin and propagation that for full description of the ground vibration it is necessary, in addition to three translational components and strain, to consider also three rotational components (e.g. Båth, 1979; Teisseyre et al., 2006; Lee et al., 2009). The classic way of measuring rotations by using two identical pendulums was apparently first suggested by Golitzin (1912 in (Graizer, 2009)). Traditionally, only the translational components of the earthquake ground vibration and structural response have been recorded. In part, the absence of instrumental observations of rotational motions resulted from lack of inexpensive rotational sensors of sufficient sensitivity to record and measure small ground rotations caused by earthquakes. The rotations in structural response and the contributions to the response from the rotational components of the ground motion have also been points of interest for last decades (Todorovska et al., 2008). The Russian pendulum seismometer S-5-S appeared as suitable for modification for the recording of rotational components of ground motion around the vertical or horizontal axis. This S-5-S modification was realized by specialists of the Institute of Geonics, ASCR, in 2010 (Knejzlík et al., 2012).

Karvina area (Upper Silesian Coal Basin, Czech Republic), in which foci of mining induced seismic events were localized in the vicinity of local seismic stations (Doležalová et al., 2008; Holub et al., 2009; Kaláb et al., 2011a), was selected to verify the functionality of the S-5-5R rotational sensors in the field conditions. Measurement in near-source area is necessary because rotational components are quickly attenuated. Our first records of rotational component were obtained during the experimental seismic monitoring in 2010/11 and 2011/12 that confirmed rotational component existence - besides natural earthquakes - also for the mining induced seismic events. The values of ground rotational motion around the vertical axis recorded in the seismic station at Doubrava village exceeded value of $1 \mathrm{mrad}^{-1} \mathrm{~s}^{-1}$ (Kaláb and Knejzlík, 2012).

\section{S-5-SR SENSOR}

Kharin and Simonov (1969 in Graizer, 2009) implemented measuring system by using two identical pendulums on the same axis (instrument called VBPP). Detailed discussion about this type of measuring system including theoretical equations was described in papers presented by Graizer (2006, 2009). The mechanical system of the original S-5-S seismometer consists of electrodynamic sensing and damping transducer coils mounted on asymmetrical double-arm pendulum. Modification of the S-5-S seismometer into the S-5-SR seismometer consisted of removing the additional spring and appending additional mass on the damping arm. This new mass 


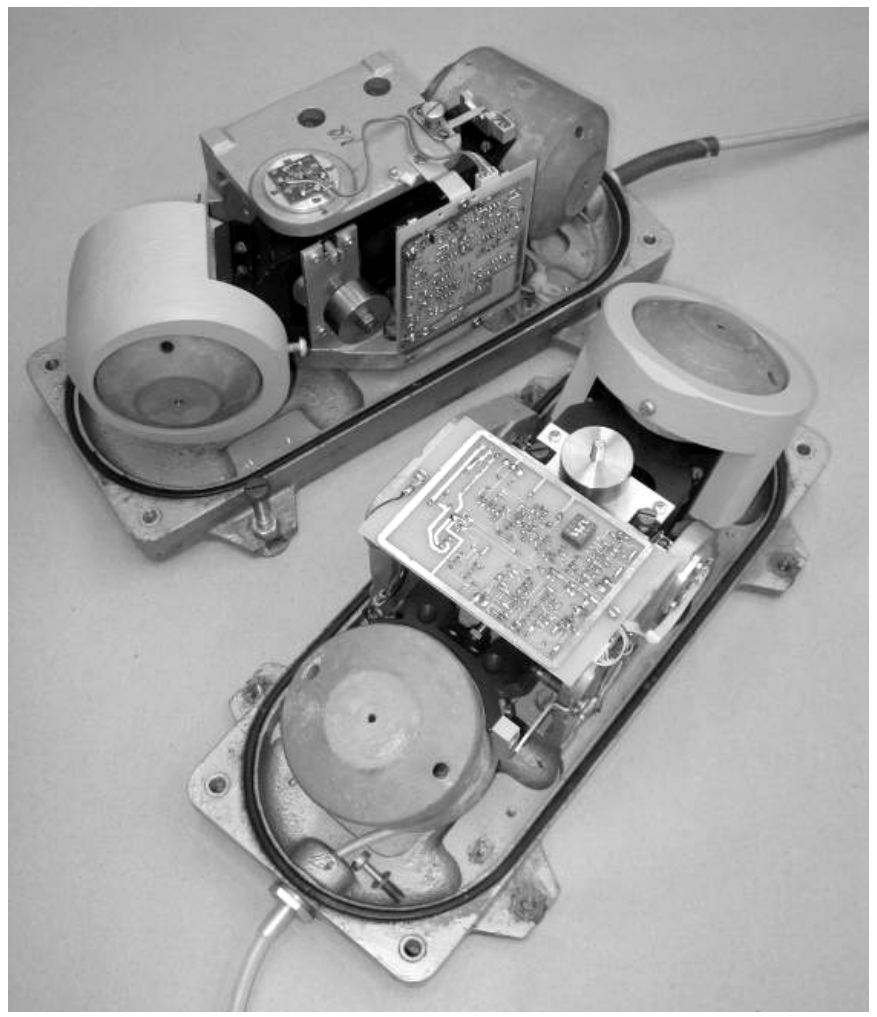

Fig. 1 The S-5-SR sensor recording rotational components of ground vibrations around the vertical axis (behind) and around the horizontal axis (in front); both sensors without covers.

was used for rough balancing the pendulum centre of gravity into axis of rotation. The precise balance is realized using two independent balancing weights mounted on perpendicular set-screws. Routine of precise balancing is described in (Knejzlík et al., 2010). It means that main measuring element is very well balanced two-armed lever. Strain-gauge angle sensor is installed on one pair of flat spring. Main dynamic parameters of the modified rotational sensor, e.g., its natural period and its damping were controlled electronically by feedback of angular displacement and angular velocity, both conducted to the damping transducer coil. For detailed information about the modification of S-5-S see papers by Knejzlík et al. (2011, 2012).

Modified Russian seismometer S-5-SR enables to record rotational components of seismic ground vibrations in the frequency range $0.2-25 \mathrm{~Hz}$. Industrial Property Office of the Czech Republic has registered the Utility model for this modification in 2011. This is one-component sensor that can record rotational ground motion around either vertical or horizontal axis (Fig. 1). It is designed to obtain either velocity or displacement of rotational motion.

The basic tests of modified sensor S-5-SR were realized by means of shaking table at the Geophysical Institute ASCR, Prague (Knejzlík et al., 2012; Fig. 2). Output signal levels for rotational (R) and translational $(\mathrm{T})$ excitations are presented in Figure 3. The sensitivity constant for angular velocity $k(d \varphi / d t)=52.6$ V.s.rad ${ }^{-1}$ was obtained over a range of oscillation velocity up to $10 \mathrm{mrad} . \mathrm{s}^{-1}$. The sensitivity constant $k(\varphi)=1393 \mathrm{~V} \cdot \mathrm{rad}^{-1}$ was measured outside the angular displacement channel. The clamp amplitude is limited to $+/-0.015 \mathrm{rad}$ due to the inhomogeneous magnetic fields of the electrodynamic transducers used in the original S-5-S seismometer. Natural noise of S-5-SR seismometer is $1 \mu \mathrm{rad} . \mathrm{s}^{-1}$ for frequency below $1 \mathrm{~Hz}$.

\section{FIELD TESTS}

Initial information about experimental field tests in the Karvina region was published by Kaláb and Knejzlík (2012). The results obtained during field testing of S-5-SR at the Doubrava region operating between Dec 13, 2010, and Jun 13, 2011, and at the Orlova region, operating Sep 12, 2011- Feb 22, 2012 were collected and interpreted in detail. The tested seismic sensor S-5-SR was installed in the basement floor of large building. The sensor was connected to the digital seismological apparatus PCM3-EPC type, in which the records were digitized using $100 \mathrm{~Hz}$ sampling frequency, which is sufficient in relation to the frequency range of the sensors. Record examples of translational components of ground vibration velocity and the rotational component of ground 


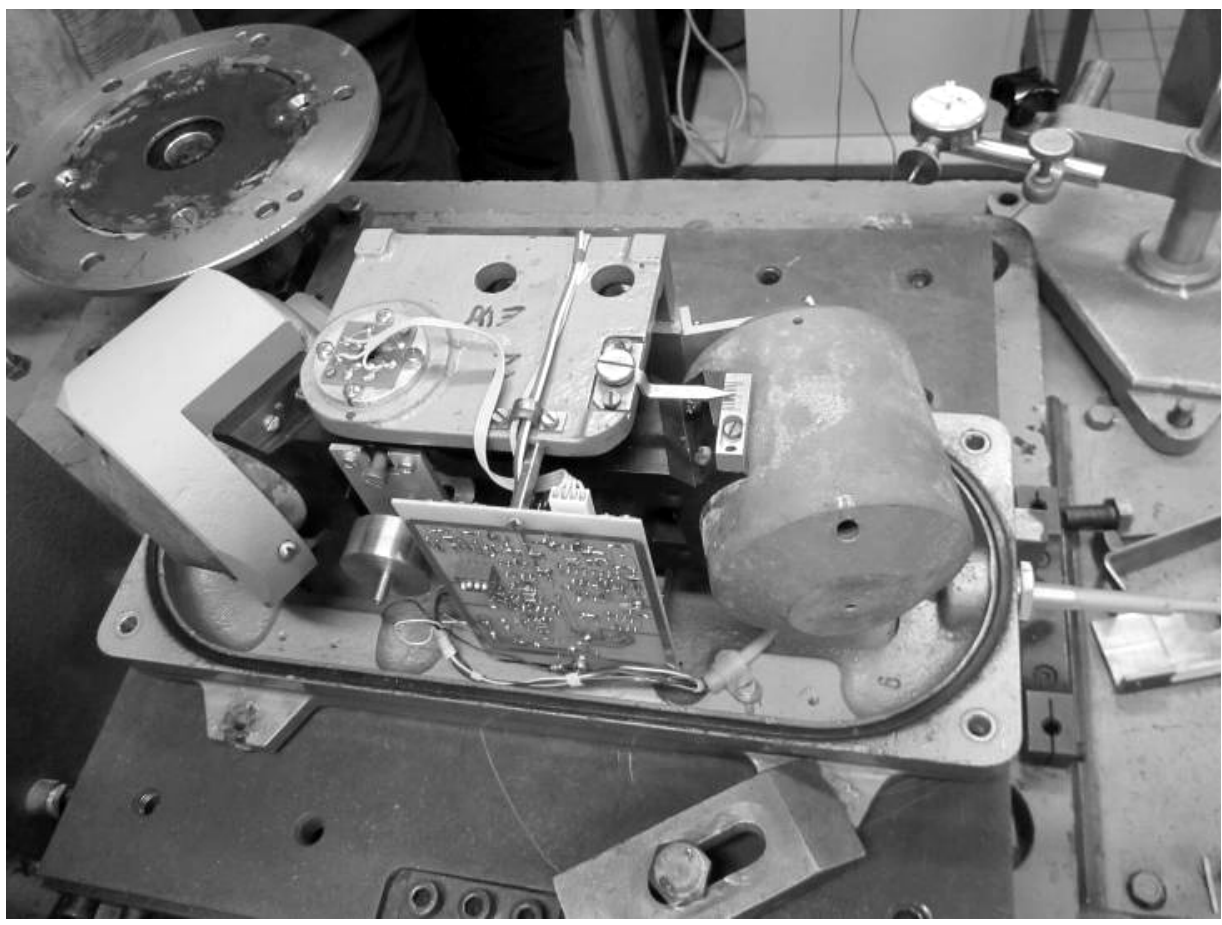

Fig. 2 The S-5-SR sensor recording rotational components of ground vibrations around the vertical axis during tests on the shaking table in the Geophysical Institute of the ASCR, Prague; without cover.

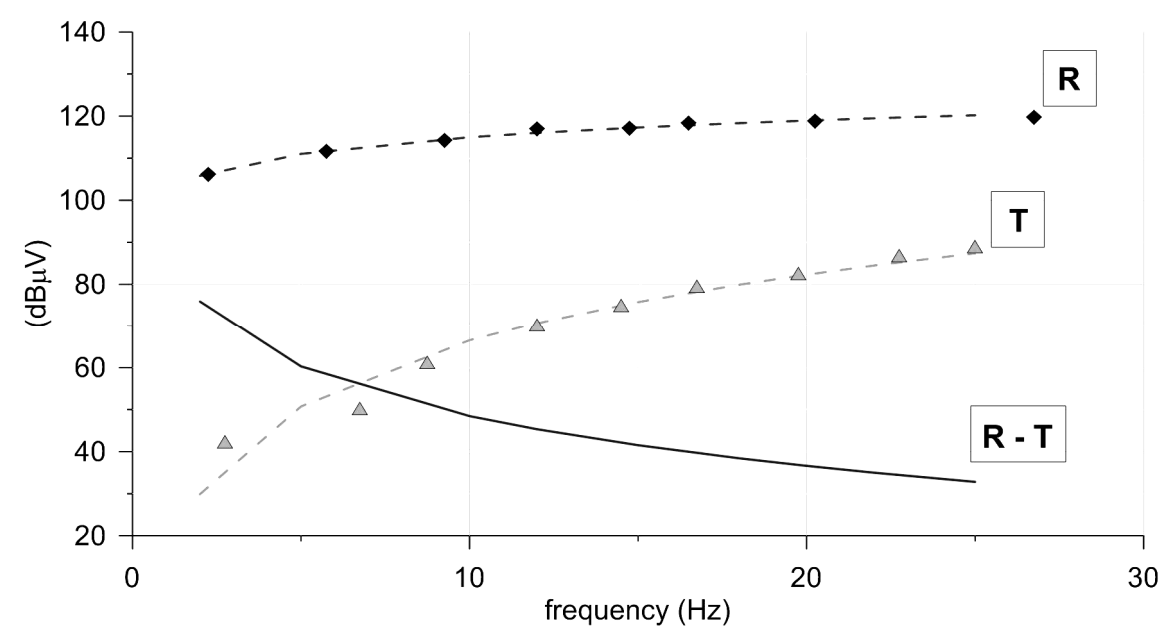

Fig. 3 Output signal levels for rotational (R) and translational (T) excitations of S-5-SR. In both cases double amplitude of SET vibrations was $50 \mu \mathrm{m}$. $\mathrm{R}-\mathrm{T}$ curve represents attenuation of translation component. $(120 \mathrm{~dB} \mu \mathrm{V}=1 \mathrm{~V})$.

vibration velocity around the vertical axis are presented in Figure 4. On the left, record of wave pattern from Orlova seismic station is presented. Hypocentral distance of this strong mining induced seismic event (Jan 1, 2012) was $1.8 \mathrm{~km}$, seismic energy was $9.5^{*} 10^{6} \mathrm{~J}$. The maximum measured value of rotational velocity was almost 0.15 mrad. $\mathrm{s}^{-1}$; the maximum measured translational velocity was $2.6 \mathrm{~mm} . \mathrm{s}^{-1}$. Presented wave pattern on the right was recorded on Doubrava seismic station. This record represents more intensive mining induced seismic event (Dec 21, 2010) from hypocentre distance about $1 \mathrm{~km}$, seismic energy was $2.6^{*} 10^{5} \mathrm{~J}$. The maximum measured value of rotational velocity was almost 0.3 mrad. $\mathrm{s}^{-1}$; the maximum measured translational velocity for this event has reached up nearly $8 \mathrm{~mm} \cdot \mathrm{s}^{-1}$. Interpretation of wave patterns was made by routine seismological software package and also using 

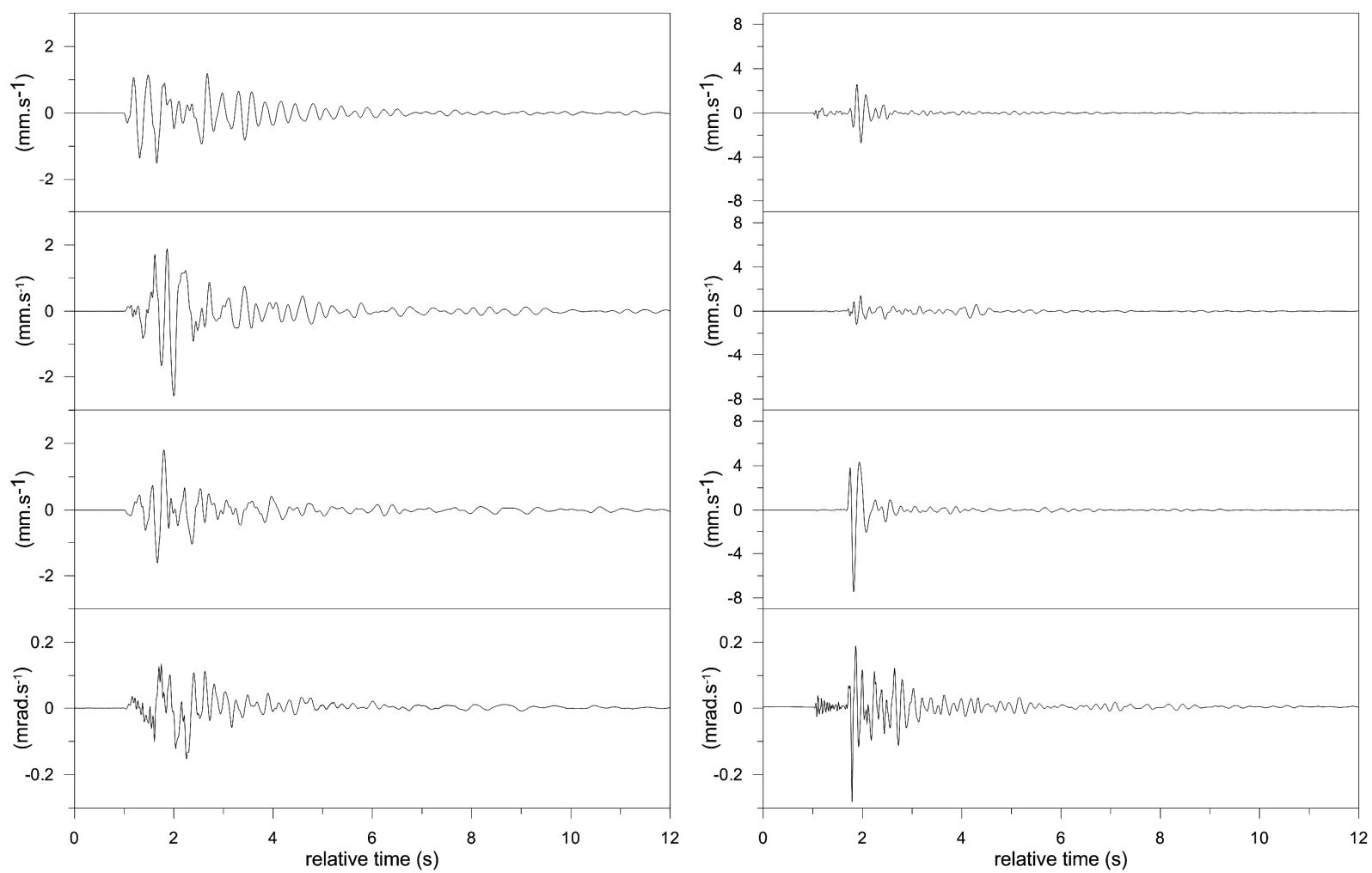

Fig. 4 Examples of translational components of ground vibration velocity (down from top vertical, horizontal $\mathrm{N}-\mathrm{S}$, horizontal E-W components) and the rotational component of ground vibration velocity around the vertical axis (last component); on the left - Orlova seismic station, on the right - Doubrava seismic station; along the horizontal axis relative time is plotted.

wavelet transform (Lyubushin et al., 2004; Kaláb et al., 2011b).

From the geological viewpoint, locality of Doubrava presents Carboniferous rock massif covered by Tertiary sedimentary rock of thickness of $650 \mathrm{~m}$ (sandstones, argillites and conglomerates of various solidification degree). Seismic station at Orlova village was located in the area in which no sedimentary rock occurred except of deluvial and sandy loams - so called "Carboniferous window" (e.g. Dopita et al., 1997; Kaláb and Knejzlík, 2002). During monitoring period, more than 200 mining induced seismic events were recorded on each seismic station in the Doubrava and the Orlova regions. This is quite large amount of the data to make the first analysis of measured values of rotational velocity compared with the energy and hypocentral distance of events in two localities with the different geological conditions. Maps of epicentres for studied data sets are presented in Figure 5 (using database of Green Gas DPB a.s.). Positions of seismic stations Orlova and Doubrava are marked by a triangle.

Data recorded at Doubrava seismic station represent mining induced seismic events in wide range of hypocentral distances from $0.8 \mathrm{~km}$ up to $30 \mathrm{~km}$. The seismic energy recorded ranged from $4.5^{*} 10^{2} \mathrm{~J}$ up to $2.8^{*} 10^{6} \mathrm{~J}$. Events of hypocentral distances above $18 \mathrm{~km}$ represent mining induced seismic events, which originated in Polish part of coal basin (epicentres of these events are out of the map in Figure 5). Large amount of the events recorded at Doubrava seismic station originated at the depths from $0.7 \mathrm{~km}$ to $1 \mathrm{~km}$ under the surface and this seismic activity is connected with the coalface mined out almost below the seismic station.

At Orlova seismic station it is quite different situation. Hypocentral distances of recorded mining induced seismic events vary only from $1 \mathrm{~km}$ up to $8 \mathrm{~km}$, seismic energy ranges from $4.1 * 10^{2} \mathrm{~J}$ up to $1.4 * 10^{7} \mathrm{~J}$. It was not possible to analyze rotational component of strong events from far distances, because of small values of rotational velocity vanishing in seismic noise.

\section{INTERPRETATION OF FIELD TESTING RESULTS}

Diagrams in Figure 6 represent relation of maximum rotational velocity values vs. hypocentral distances for recorded events, simultaneously, intervals of seismic energy of the events were also determined. Figure 6 on the left represents data recorded at Doubrava seismic station. It was possible to detect rotational component at Doubrava seismic station for the events of energy order of $10^{2} \mathrm{~J}$ 
Table 1 Selected parameters of mining induced seismic events presented in Figure 7 and their maximum values of rotational component (values of distance, depth and seismic energy from database of Green Gas DPB a.s.).

\begin{tabular}{|c|c|c|c|c|}
\hline & $\begin{array}{c}\text { Epicentral } \\
\text { distance / depth } \\
{[\mathrm{km}]}\end{array}$ & $\begin{array}{c}\text { Seismic } \\
\text { energy }[\mathrm{J}]\end{array}$ & $\begin{array}{l}\text { Max. value of rotational } \\
\text { component }\left[\operatorname{mrad}^{-1} \mathrm{~s}^{-1}\right]\end{array}$ & $\begin{array}{c}\text { Position of wave } \\
\text { pattern in Figure } 7 \\
\text { (down from top) }\end{array}$ \\
\hline $\begin{array}{c}\text { Doubrava seismic } \\
\text { station }\end{array}$ & $1.46 / 0.80$ & $1.7 * 10^{6}$ & 0.30 & 1 \\
\hline $\begin{array}{l}\text { Orlova seismic } \\
\text { station }\end{array}$ & $1.60 / 0.74$ & $9.5^{*} 10^{6}$ & 0.15 & 2 \\
\hline $\begin{array}{c}\text { Doubrava seismic } \\
\text { station }\end{array}$ & $3.13 / 0.70$ & $4.5^{*} 10^{5}$ & 0.03 & 3 \\
\hline $\begin{array}{l}\text { Orlova seismic } \\
\text { station }\end{array}$ & $2.91 / 0.83$ & $7.4 * 10^{5}$ & 0.017 & 4 \\
\hline $\begin{array}{c}\text { Doubrava seismic } \\
\text { station }\end{array}$ & $5.06 / 0.71$ & $2.8^{*} 10^{5}$ & 0.008 & 5 \\
\hline $\begin{array}{c}\text { Orlova seismic } \\
\text { station }\end{array}$ & $5.40 / 0.75$ & $2.0^{*} 10^{5}$ & 0.0035 & 6 \\
\hline
\end{tabular}

originated in hypocentral distance up to $1.4 \mathrm{~km}$; analogously for $10^{3} \mathrm{~J}$ up to $3.2 \mathrm{~km} ; 10^{4} \mathrm{~J}$ up to $9 \mathrm{~km}$; $10^{5} \mathrm{~J}$ up to $23 \mathrm{~km}$ and $10^{6} \mathrm{~J}$ up to $30 \mathrm{~km}$.

Results from Orlova seismic station are presented in Figure 6 on the right. Up to $3 \mathrm{~km}$ of hypocentral distances, except 4 events, only events of small energy up to $10^{4} \mathrm{~J}$ were recorded. Only 13 events were recorded at Orlova seismic station for hypocentral distances $3-8 \mathrm{~km}$.

If we compare character of recorded events on discussed seismic stations, we can see the different shapes of wave patterns. Figure 7 shows six examples of this phenomenon (the wave pattern no. 6 is influenced by technical noise generated by equipment in building). Individual pairs of wave patterns (1-2, 3-4, 5-6) represent two events comparable in seismic energy from approximately same hypocentral distances. Selected parameters are presented in Table 1. Generally, rotational effect recorded at Orlova station is quickly attenuated compared with the rotational effect recorded at Doubrava seismic station. Maximum values of rotational component from Orlova seismic station are significantly lower than maximum values from Doubrava seismic station although seismic energies of events recorded at Orlova seismic station are higher or comparable. At this time, only site effect in consequence of sedimentary layers existence is taken into consideration to explain these findings. We suppose that this effect is analogous to influence of site effect on maximum values of translational components (e.g. Olszewska and Lasocki, 2004; Kaláb and Knejzlík, 2006; Kaláb and Lyubushin, 2008).

\section{CONCLUSION}

This paper presents first results of S-5-SR seismometer using for mining induced seismic events monitoring in the Karviná region. This modified seismometer enables to measure rotational velocity of vibration around vertical axis. One seismic station was installed in Doubrava village, which is area with thick sedimentary layers; second seismic station was installed in Orlova village in different local geological conditions on rock, without sedimentary layers.

Relations between hypocentral distances and maximum values of measured rotational velocity from Doubrava and Orlova seismic stations are main presented results. Examples of selected wave patterns are also included. Generally, it is possible to derive that rotational effect recorded at Orlova seismic station is quickly attenuated compared with the rotational effect recorded at Doubrava seismic station. Maximum values of rotational component from Orlova seismic station are significantly lower than maximum values from Doubrava seismic station although seismic energies of events recorded at Orlova seismic station are higher or comparable. At this time, only site effect in consequence of sedimentary layers existence is taken into consideration to explain these findings. The strongest measured value exceeded 1 mrad. $\mathrm{s}^{-1}$ at Doubrava seismic station.

From civil engineering point of view, rotational components of vibration may not present a danger for buildings and other constructions however they may cause torsional stresses loading the structures in the epicentre area, especially when the intensive seismic events occur.

\section{ACKNOWLEDGEMENT}

The work took use of the long-term conceptual development support of research organisations RVO: 68145535 . 


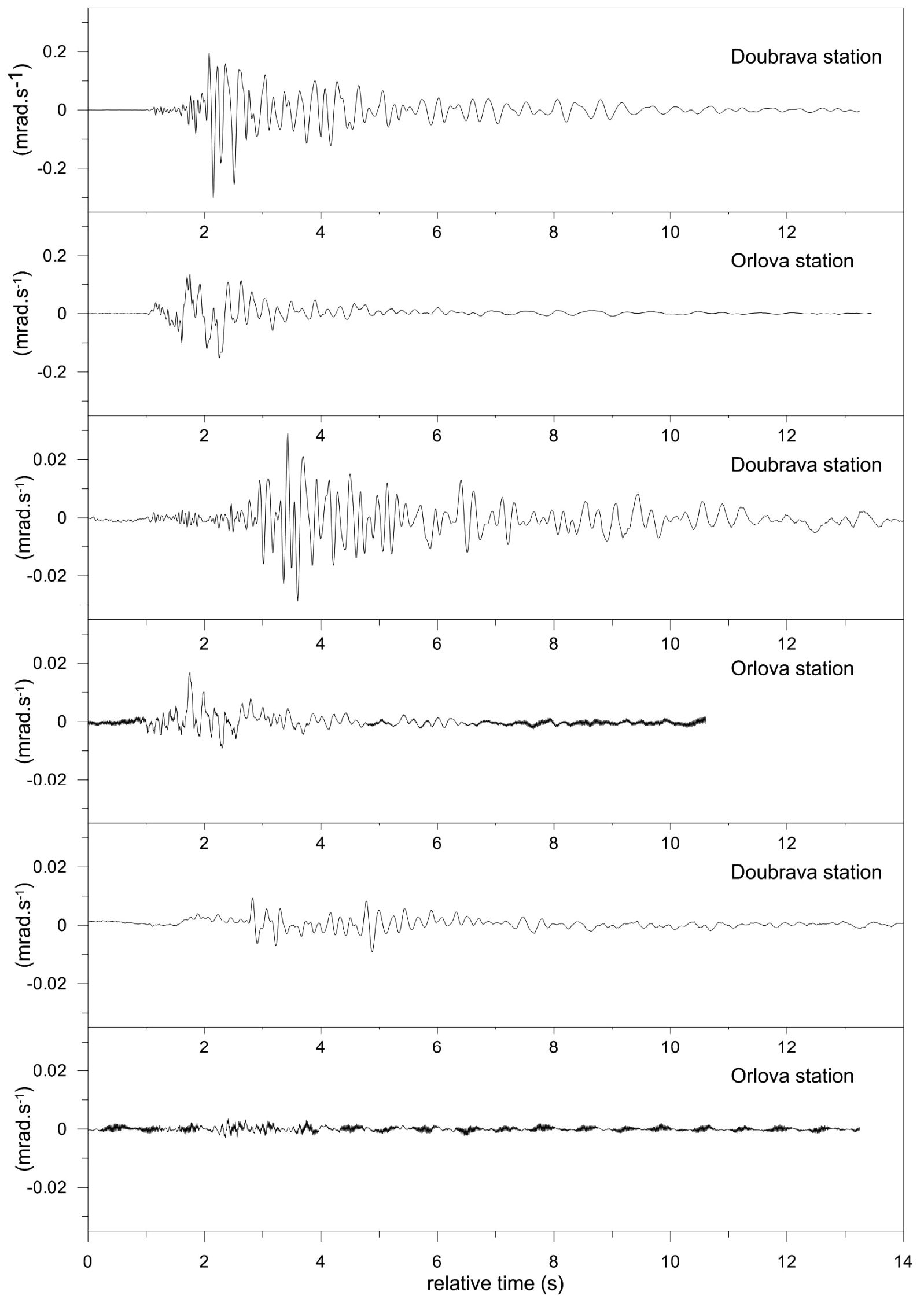

Fig. 7 Wave patterns of six selected records of rotational components of mining induced seismic events occurred in the Karvina region (for details see text). 


\section{REFERENCES}

Båth, M.: 1979, Introduction to seismology, Birkhauser Verlag, Basel.

Doležalová, H., Holub, K. and Kaláb, Z.: 2008, Underground coal mining in the Karviná region and its impact on the human environment (Czech Republic). Moravian Geographical Report, 16, No. 2, $14-24$.

Dopita, M. et al.: 1997, Geology of the Czech part of Upper Silesian Basin. Praha, MŽP ČR, 278 pp., (in Czech).

Graizer, V.: 2006, Equation of pendulum motion including rotations and its implications to the strong-motion. In: Teisseyre, R., Takeo, M., Majewski, E. (eds), Earthquake source asymmetry, structural media and rotation effects. Springer-Verlag, Berlin, 471-485.

Graizer, V.: 2009, Tutorial on measuring rotations using multipendulum systems. Bull. Seismol. Soc. Am. 99, 2B, 1064-1072. DOI: 10.1785/0120080145

Holub, K., Kaláb, Z., Knejzlík, J. and J., Rušajová, J.: 2009 , Contribution of the Institute of Geonics of the ASCR Ostrava to seismological monitoring in Silesia and Northern Moravia. Acta Geodyn. Geomater., 6, No. 3 (155), 391-398.

Kaláb, Z. and Knejzlík, J.: 2002, Systematic measurement and preliminary evaluation of seismic vibrations provoked by mining induced seismicity in Karviná area. Publs. Inst. Geophys. Pol. Acad. Sc., M-24(340), 95-103.

Kaláb, Z. and Knejzlík, J.: 2006, Field measurement of surface seismic vibrations provoked by mining in Karvina region. Publs. Inst. Geophys. Pol. Acad. Sc., M-29(395), 185-194.

Kaláb, Z. and Knejzlík, J.: 2012, Examples of rotational component records of mining induced seismic events from Karviná region. Acta Geodyn. Geomater., 9, No. 2 (166), 173-178.

Kaláb, Z., Kořínek, R., Hrubešová, E. and Lednická, M.: 2011a, Vibration on the surface due underground mining in Karviná region, Czech Republic. In: 6th Congress of the Balkan Geophysical Society, Conference Proceedings and Exhibitors'Catalogue, Budapešt', Hungary, CD, 5 pages.

Kaláb, Z., Lednická. M. and Lyubushin, A.A.: 2011b, Processing of mining induced seismic events by Spectra Analyzer software. Górnictwo i geologia. Kwartalnik, tom 6, zeszyt 1, 75-83.

Kaláb, Z. and Lyubushin, A.A.: 2008, Study of site effect using mining induced seismic events and ambient noise from Karviná region. Acta Geodyn. Geomater., 5, No. 2 (150), 105-113.
Knejzlík, J., Kaláb, Z. and Rambouský, Z.: 2010, Adaptation of pendulous seismometer S-5-S for measurement of rotation component of seismic vibrations. Proceedings of the Second Intern. Workshop on Rotational Seismology, Prague. http://geo.mff.cuni.cz/users/vackar/IWGoRS/Knejzlik.pdf

Knejzlík, J., Kaláb, Z. and Rambouský, Z.: 2011, Adaptation of pendulous seismometer S-5-S for measurement of rotation component of seismic vibrations. International Journal of Exploration Geophysics, Remote Sensing and Environment (EGRSE), XVIII.3, 72-79, (in Czech).

Knejzlík, J., Kaláb, Z. and Rambouský, Z.: 2012, Adaptation of the S-5-S pendulum seismometer for measurement of rotational ground motion. J Seismol, 16, 4, 649-656. DOI: 10.1007/s10950-012-9279-6

Lee, W.H.K., Celebi, M., Todorovska, M.I. and Igel, H.: 2009 , Introduction to the Special issue on rotational seismology and engineering applications. Bull. Seismol. Soc. Am. 99, 2B, 945-957. DOI: $10.1785 / 0120080344$

Lyubushin Jr., A.A., Kaláb, Z. and Častová, N.: 2004, Application of wavelet analysis to the automatic classification of three-component seismic records. Izvestiya, Physics of the Solid Earth, 40, No.7, 587593.

Olszewska, D. and Lasocki, S.: 2004, Application of the horizontal to vertical ratio technique for estimating the site characteristics of ground motion caused by mining induced seismic events. Acta Geophysica Polonica, 52, No. 3, 302-318.

Teisseyre, R., Takeo, M. and Majewski, E. (eds.): 2006, Earthquake source asymmetry, structural media, and rotation effects, Springer-Verlag, Berlin, 582 pp.

Todorovska, M.I., Gel, H., Trifunac, M.D. and Lee, W.H.K.: 2008, Rotational earthquake motions - International working group and its activities. The 14th World Conference on Earthquake Engineering, October 1217, 2008, Beijing, China.

http://www.iitk.ac.in/nicee/wcee/article/14_03-02-0031.pdf 

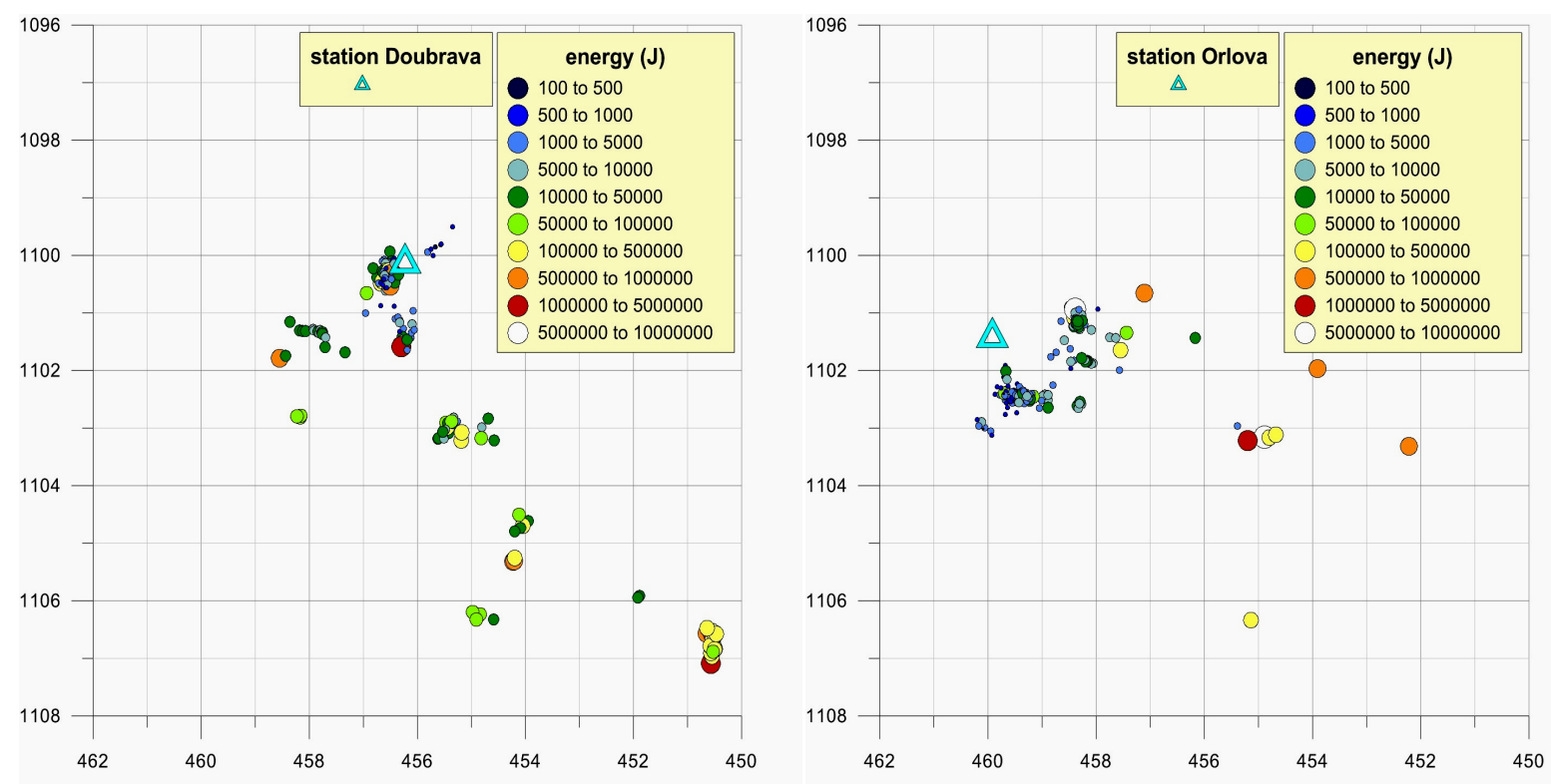

Fig. 5 Map of epicentres of mining induced seismic events, Krovak coordinates are used. On the left: analyzed data from Doubrava seismic station in the period from Dec 13, 2010 till Jun 12, 2011, on the right: analyzed data from Orlova seismic station in the period from Sep 12, 2011 till Feb 22, 2012 (the database of Green Gas DPB a.s. was used).
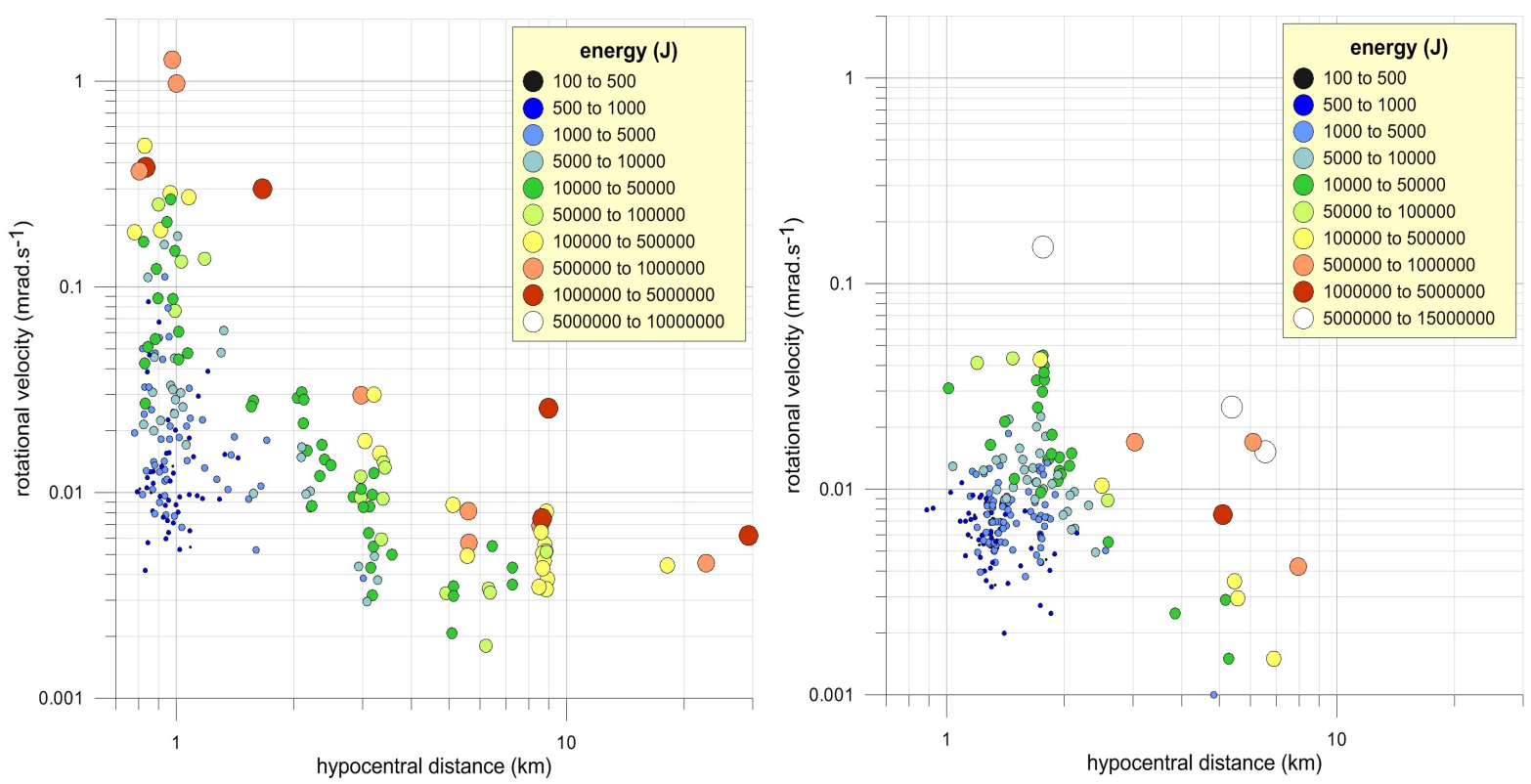

Fig. 6 Relation between hypocentral distances and maximum values of rotational velocity, on the left: data recorder at Doubrava seismic station, on the right: data recorded at Orlova seismic station; values of hypocentral distances and seismic energy were taken from the database of Green Gas DPB a.s. 